\title{
The effect of phase change on annual growth increment in eastern larch (Larix laricina (Du Roi) K. Koch)
}

\author{
M. Greenwood
}

Department of Forest Biology, University of Maine, Orono, ME 04469, U.S.A.

\section{Introduction}

Under natural conditions, a plot of the cumulative height and diameter growth by dominant trees in a given stand exhibits a sigmoid growth curve, with the maximum annual increment occurring relatively early in the age of the tree (Assmann, 1970) (Fig. 1B). The time at which the maximum increment occurs appears to be speciesspecific and occurs earlier for pioneer species like pine (see Fig. 1A). Such observations have led some growth and yield scientists to conclude that a tree undergoes several distinct growth phases during its development in a stand, referred to as physiological ageing (e.g., Assmann, 1970). For example, a phase where annual increment reaches a maximum value (the 'phase of full vigor' according to Assmann), followed by a so-called mature phase where annual increments decline, then stabilize, have been proposed, but the role of tree size or maturation state as a basis for these phases is not discussed.

Assmann (1970), using data from von Guttenberg (1885), showed that for Norway spruce the maximum annual increment for both height and diameter occurs later on relatively poorer sites (Fig. $1 \mathrm{~A}$ and $B)$. The trees were approximately the same height $(7-8 \mathrm{~m})$ when the maximum increment occurred, but the tree on the moderate quality site attained this height at age 34 , compared with age 23 on the top quality site. Diameter growth increments appeared to follow a pattern similar to that for height growth. One interpretation of these observations is that annual increment is in part determined by the maturation state of the tree, which in turn is a function of size, not chronological age. The decline in annual increment will also be affected by competition from other trees for light, water and nutrients. However, the earlier decline in annual increment observed for a dominant tree on a relatively good site is probably not due to the limiting effect of competition or nutrients (Forward and Nolan, 1964), but instead may be due to an inherent decline in growth potential.

There is little doubt that the maximum size a tree can attain is primarily a function of its genetics. While white pine, red spruce and eastern larch can all grow on similar sites, white pine can achieve a much greater maximum size or age (500 

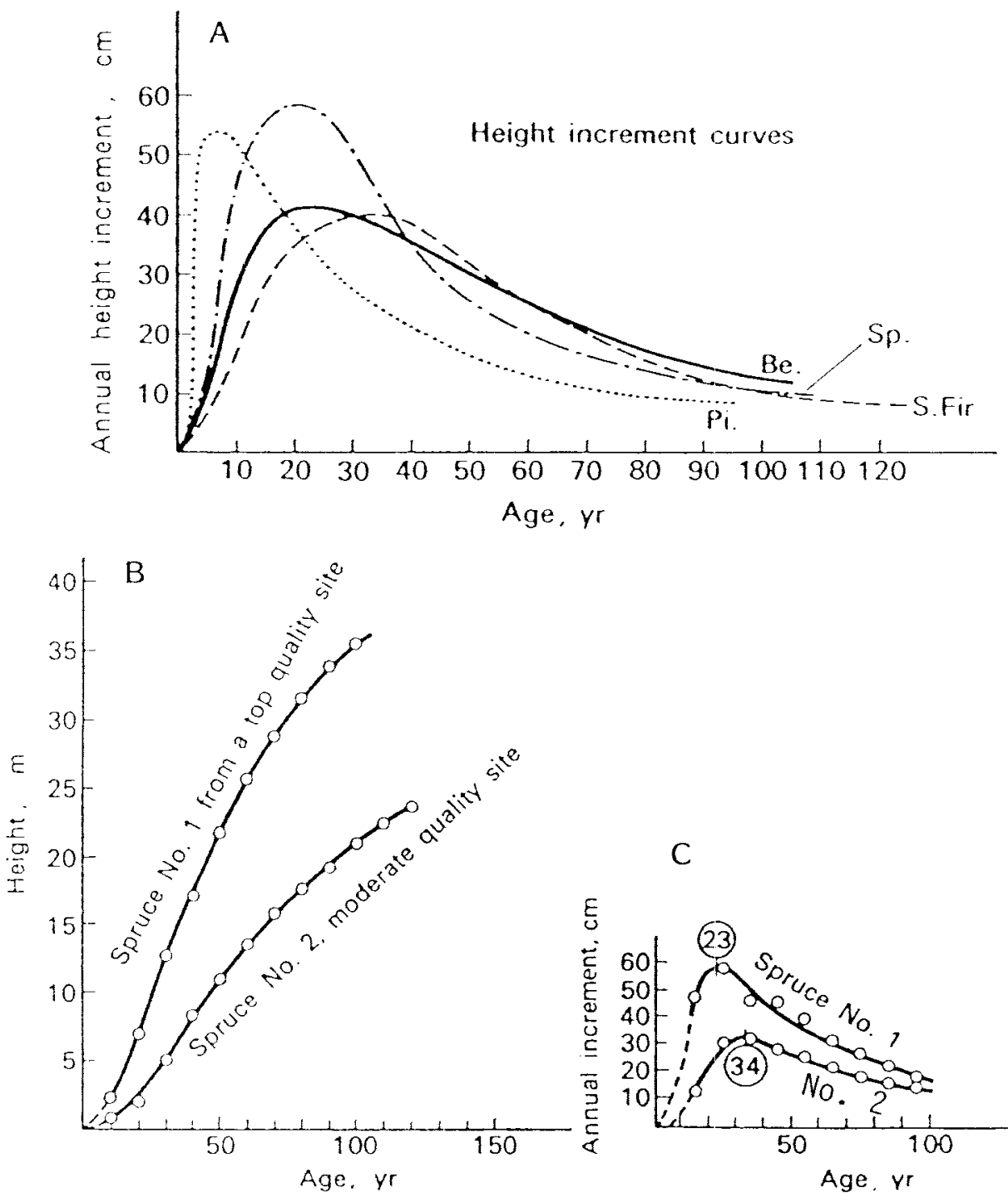

C

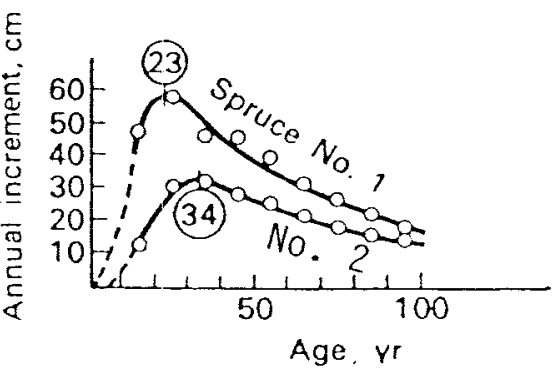

Fig. 1. A. Annual height increment curves for spruce (Sp.), beech (Be.), fir ( $\mathrm{S}$. Fir) and pine (Pi.) all growing on comparable sites. B. Height growth curves for 2 Norway spruce trees, one growing on a top quality site, the other on a moderate quality site. C. Annual height increment curves for the 2 trees in $B$; number in circle indicates age at which annual increment reaches a maximum. Graphs based on data from von Guttenberg (1885, original not seen) as portrayed in Assmann (1970).

vs $200 \mathrm{yr}$ ) compared to larch, but the early growth rates of both species are relatively rapid (Altman and Dittmer, 1962, original not seen; data presented in Kozlowski, 1971). Red spruce exhibits relatively slow early growth, but lives much longer than 
larch $(300 \mathrm{yr})$. The maximum diameters for larch and red spruce range from 30-60 $\mathrm{cm}$, compared with $60-120 \mathrm{~cm}$ for white pine. These differences result from inherently different growth patterns, which not only determine the optimum rotation age for the species, but also must be considered during plus tree selection. This raises a fundamental question: what (if any) is the magnitude of the effect of genotype on the relationship between growth increment and tree age? The purpose of this paper is to discuss the impact of phase change or maturation on growth potential and how these changes affect the shape of the growth curve for a particular species. Growth potential as a function of age is demonstrated here by grafting scions (of the same diameter and length) from different aged trees onto uniform rootstock and observing their growth under controlled conditions.

\section{Materials and Methods}

Scion material was collected from a naturally seeded larch stand near Bingham, ME, U.S.A. Three distinct age classes $(3-7,16-19$ and 33-74 yr) were identified from increment cores taken from the boles of sample trees at $50 \mathrm{~cm}$ above groundline. Since no $1 \mathrm{yr}$ old seedlings could be found in the stand, scions were collected from container-grown seedlings originating from 5 open-pollinated trees.

Scions were taken from vigorous terminal long shoots of lateral branches in the upper quadrant of the live crown, and then decapitated and trimmed to a length of $20 \mathrm{~cm}$, so that all were about the same diameter. Consequently, all shoots developed from lateral buds on primary branches, so topophytic effects were minimized. All scions were grafted in March, 1986, onto 2 yr old rootstock. Graft survival across all 4 age classes ranged from 91 to $100 \%$, resulting in a total of 150 grafts.

Height (from the graft union) and diameter (just above the graft union) measurements were taken at the end of each growing season. In addition, the primary branches were counted on the main stem. All grafts were visually scored for orthotropic vs plagiotropic growth after the first growing season. Scions whose leaders were growing close to vertical were considered orthotropic, while scions growing horizontally or at clearly less than vertical were called plagiotropic.

\section{Results and Discussion}

The annual diameter increments for 2 larch trees, both dominants, are shown in Fig. 2C. Tree 1 is located in a moist area with good drainage and deep soil, while tree 2 is located about $100 \mathrm{~m}$ away on a very rocky but similarly moist site. Both trees faced little competition in their early years, since they both exhibit thick, long branches near the base of the trunk, which are typical of open grown trees. The maximum annual increment was attained later for tree 2, and was considerably less than the maximum for tree 1 . The annual increment curves are somewhat similar to those for Norway spruce shown in Fig. 1C, and the differences between them are probably also due at least in part to site. Trees immediately adjacent to tree 1 or 2 exhibited similar diameter increment patterns. Since the annual increment patterns for tree 1 and 2 are quite different, probably because of microsite differences, their rates of maturation may also have been different.

Reduced growth potential with increasing age has been demonstrated by grafting scions from trees of different ages onto uniform rootstock and comparing the subsequent development as a function of age (e.g., Sweet, 1973; Greenwood, 1984). A similar experiment was carried out using the larch trees in the stand described above (Greenwood et al., 1989). Grafting success was not affected by the age of the donor tree. The height and diameter increments of the grafted scions after the first growing season are shown in Fig. $2 \mathrm{~A}$ and 

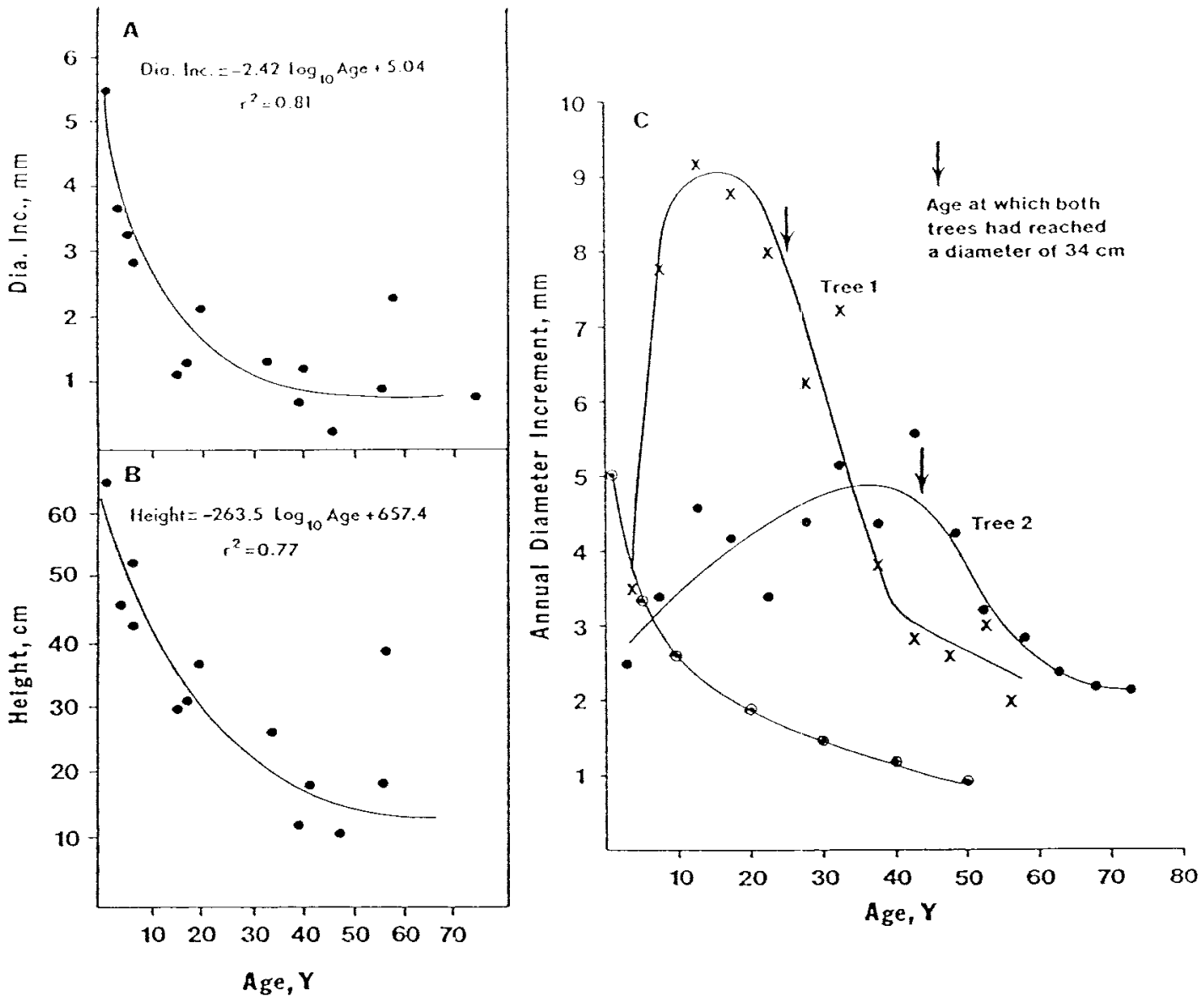

Fig. 2. A. and B. Diameter and height growth potential for eastern larch as a function of age. as demonstrated by following the growth of scions grafted from trees of different ages. Each point is the mean of all surviving (after I yr) scions grafted from trees of the ages shown, with $n$ ranging from $5-29, \bar{X}=10$. Although 27 trees were sampled originally, a number were the same age, resulting in 14 different age groupings. C. Annual increment curves $(x-x$ and $\bullet-$ ) for 2 larch trees growing on relatively different sites (see text). Arrows indicate the age when each tree has reached a similar diameter. Diameter growth potential curve (0-0) derived from the equation shown in $A$.

B. Height and diameter growth increments decrease with increasing age, and follow a similar pattern. The effects of age were statistically significant $(P<0.0001)$ according to ANOVA. Clearly, there has been a decline in scion growth potential with increasing age, which results in reduced shoot growth in the first growing season after grafting. While this decline may have resulted from increasing size of the donor tree, it cannot be reversed immediately by grafting onto young trees. The short shoot buds on scions of all ages all began to flush about 2 weeks after grafting and long shoots developed from the most apical shoots within several weeks. Except for the scions from 1 yr old trees, most of the long shoots grew plagiotropically (Green- 
wood et al., 1989) and progressively more slowly with increasing age, even though all were staked upright.

The age-related differences in size were maintained in the following years and became even more pronounced. Also, successfully rooted cuttings taken from lateral branches of the developing scions continued to reflect the growth of the scion itself, although the root systems which regenerated were progressively poorer with increasing age (Foster and Adams, 1984; unpublished data). However, if either the height or diameter increment is expressed as a percentage of total size attained by the scion alone the previous year, the percentage for the older scions actually becomes somewhat greater than that for younger scions in the second growing season. In contrast, in the first growing season, the growth increment of the younger scions is much greater as a percentage of the original scion dimensions. Thus the older scions have been relatively reinvigorated to some extent and can produce proportionately as much growth as the younger ones, but only in the second growing season after grafting. The same results were obtained during a similar experiment with loblolly pine (Greenwood, 1984).

This apparent reinvigoration may be related to the removal of the competing effects of the juvenile rootstock foliage, which was gradually pruned away during the first growing season. The age-related difference in growth potential may be exaggerated by a progressive inability of older grafted shoots to compete with those of the rootstock for the inputs from the root system, in contrast to the younger scions. Conversely, the increased growth potential of the mature scions, once the competing juvenile foliage of the rootstock has been removed, may be exaggerated by the proximity to the vigorous root system of the rootstock. But other mature charac- teristics, like chlorophyll content, foliar morphology and reproductive competence have persisted for several years (Greenwood et al., 1989).

The decline in growth potential demonstrated by grafting and the change in annual diameter growth increment observed in 2 of the older trees in the natural stand is shown in Fig. $2 \mathrm{C}$. The diameter growth potential has been estimated from the curve in Fig. 2A. There are many difficulties in trying to relate the growth potential of scions grafted from trees of different ages to the pattern of annual diameter increment shown in time by intact trees. Since the scions were twigs taken from the terminal long shoots of primary branches, their diameter increments in the first year after grafting cannot be expected to be as great as those from the main stems on intact trees. Also, is the decline in growth potential of the scions only a function of shoot elongation potential, which in turn limits diameter growth? At present, we do not know whether or not phase change affects both apical and cambial meristems. Nonetheless, although difficult to describe, there probably is a relationship between the growth potential and annual increment curves.

While growth potential of grafted scions decreases steadily after age $1 \mathrm{yr}$, the annual diameter increment of trees 1 and 2 increased until about age 10-15 yr, then began to decline for tree 1 , but plateaued for tree 2. The growth potential of a scion from a $1 \mathrm{yr}$ old plant placed onto a welldeveloped rootstock cannot be expected to reflect the actual growth observed during the first few years in the field, while the seedling is small. That a newly germinated seedling cannot produce a maximum annual increment in height and diameter after $1 \mathrm{yr}$ is intuitively obvious, but maximum growth potential is clearly necessary for the seedling to establish itself. In addition, scions from $1 \mathrm{yr}$ old 
trees produced 2-3 times more branches per unit length of stem than older ones (Greenwood, 1984; Greenwood et al., 1989), which may also be a result of the vigorous growth potential of young trees. After 5-10 yr, the plant will have become well enough established to realize its growth potential to the fullest extent. Before $10 \mathrm{yr}$, the tree has not developed the productive capital (in terms of photosynthetic or absorbtive root surface area) needed to fully realize its growth potential.

The growth potential curve in Fig. $2 \mathrm{C}$ is based on the performance of grafted scions growing under controlled conditions, while the annual increment curves were taken from trees growing on 2 contrasting sites. Nonetheless, the annual increment curves follow the same general pattern, but the period during which growth increment was maximized was much longer for tree 2. The annual diameter increment for both trees began to drop sharply when a total diameter of about $35 \mathrm{~cm}$ was reached. This occurred at about age 25 for the faster growing tree 1 , but did not occur until age 44 for tree 2 (see arrows in Fig. 2C). The decline in growth potential exhibited by the grafted scions began to plateau out at about $20 \mathrm{yr}$, well before the annual increments for both trees had reached a minimum. One conclusion from these observations is that the slower growing tree 2 may have lost growth potential at a slower rate than tree 1 , due to its rocky, thin-soiled microsite. Since both trees were about the same diameter when the decline in annual increment became pronounced, the decline may be related to the consequences of reaching a critical size. Height growth analysis has not yet been performed on these trees, but these observations are consistent with those (discussed earlier) made on height growth of Norway spruce.

While the shape of the growth increment curve for a given tree will, in part, be determined by site, there may be a genetic component as well. In this paper, we can only raise the question of the impact of genetic variation in growth potential (as defined here) on the increasing and decreasing phases of the annual increment curve. Unfortunately, observations on the effect of age on the growth potential for a select, mature tree are not possible in the absence of proven techniques of rejuvenation. Therefore, at present, we can only speculate as to whether or not shape of a growth potential curve will differ among genotypes. For example, do some trees have relatively low growth potential when young, but relatively higher potential when mature, or vice versa? The variation in growth periormance between scions from the same tree, combined with a sample size maximum of only 5 scions per tree did not allow detection of significant growth potential differences between trees of the same age which are of very different sizes.

The results reported here also bear on the nature of the mechanism that causes phase change. Is the phase change process a consequence of: 1) the amount of growth that has occurred, or 2) is it the result of the physiological consequences of increased size? For example, is the progression of phase change a function of the number of cell divisions that has occurred in the apical meristem (Robinson and Wareing, 1969), or is it due to changed physiological inputs (like increased water stress or changes in root-produced hormone levels) to the meristem (Borchert, 1976)? In either case, a grafted scion 'remembers' the maturation state of the tree it came from. The results presented here show that phase change (in terms of height and diameter growth) may occur faster in faster growing trees, which would not be expected if phase change is a function of physiological stress. Assuming similar stocking levels and other forms of 
competition, trees of similar size on a good and poor site will not be experiencing the same levels of stress; the tree on the poor site may be under greater stress which will result in relatively less height and diameter growth each year, yet may lose growth potential more slowly. However, trees on relatively poor sites sustain a maximum annual growth increment for a longer time (see Figs. $1 \mathrm{C}$ and $2 \mathrm{C}$ ), which suggests that size and not stress determines when annual increment begins to decline. One possible test of this hypothesis would be a comparison of the growth potential of large numbers of grafted scions from trees of exactly the same age, but of very different sizes. A large number of comparisons (about 15) would be required because of the possible additional effects of genotype on growth potential.

\section{Acknowledgments}

I would like to thank Drs. R. Briggs and K. Hutchison for their critical review of this paper.

\section{References}

Assmann E. (1970) In: The Principles of Forest Yield Study. Pergamon Press Ltd., New York, pp. 506

Borchert R. (1976) The concept of juvenility in woody plants. Acta Hortic. 56, 21-33

Forward D.F. \& Nolan N.J. (1964) Growth and morphogenesis in the Canadian forest species. VII. Progress and control of longitudinal growth of branches in Pinus resinosa ait. Can. J. Bot. 42, 923-950

Foster G.S. \& Adams W.T. (1984) Heritability, gain and $C$ effects in rooting western hemlock cuttings. Can. J. For. Res. 14, 628-638

Greenwood M.S. (1984) Phase change in loblolly pine: shoot development as a function of age. Physiol. Plant. 61, 518-522

Greenwood M.S., Hopper C.A. \& Hutchison K.W. (1989) Maturation in larch. I. Effect of age on shoot growth, foliar characteristics, and DNA methylation. Plant Physiol. 90, 406-412

Kozlowski T.T. (1971) In: Growth and Development of Trees, Vol. 1: Seed Germination, Ontogeny and Shoot Growth. Academic Press, New York, pp. 443

Robinson L.W. \& Wareing P.F. (1969) Experiments on the juvenile-adult phase change in some woody species. New Phytol. 68, 67-78 Sweet G.B. (1973) The effect of maturation on the growth and form of vegetative propagules of radiata pine. New Zealand J. For. Sci. 3, 191210 